
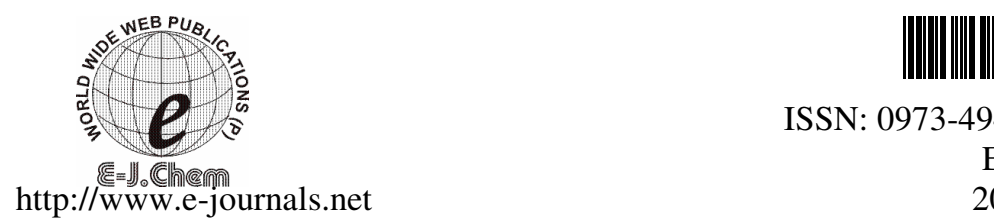

ISSN: 0973-4945; CODEN ECJHAO

E-Journal of Chemistry

2010, 7(S1), S481-S487

\title{
Catalytic Spectrophotometric Method for Determination of Formaldehyde Based on its Catalytic Effect on the Reaction Between Bromate and Safranin
}

\author{
MOHSEN KEYVANFARD \\ Faculty of Science \\ Islamic Azad University-Majlesi Branch, Isfahan, Iran \\ keyvan45638@yahoo.com
}

Received 23 January 2010; Accepted 3 April 2010

\begin{abstract}
The reaction monitored spectrophotometrically by measuring the decrease in absorbance of the reaction mixture at $533 \mathrm{~nm}$. The fixed-time method was used for the first $60 \mathrm{~s}$. For initiation of the reaction, under the optimum conditions, in the concentration range of $0.02-1.5 \mu \mathrm{g} \mathrm{mL}^{-1}$ formaldehyde can be determined with a limit of detection $9.5 \mathrm{ng} \mathrm{mL}^{-1}$. The relative standard deviation of five replicate measurements is $2.3 \%$ for $0.5 \mu \mathrm{g} \mathrm{mL} \mathrm{L}^{-1}$ of formaldehyde. The method was used for the determination of formaldehyde in water samples with satisfactory results. A new simple and fast catalytic kinetic method for the determination of trace amount of formaldehyde is described. The method is based on the catalytic effect of formaldehyde on the oxidation of safranin by bromate in the present of sulfuric acid.
\end{abstract}

Keywords: Catalytic, Safranin, Formaldehyde, Determination; Bromate.

\section{Introduction}

Formaldehyde is a flammable, colorless and readily polymerized gas at ambient temperature. Exposure to formaldehyde has caused intense concern because it is an irritant giving rise to dermatitis, eye irritation, respiratory irritation, asthma, and pulmonary edema $^{1,2}$ It has the potential to react with hydrochloric acid to form bis(chloromethyl)ether a known carcinogen ${ }^{3,4}$. Industrial exposure to formaldehyde occurs mainly in the woodworking and garment industry using formaldehyde based resins. Because of its widespread use and adverse health effects, Interest in improved analytical methodology for the determination of formaldehyde is high. Various methods have been developed for the determination of formaldehyde including $\mathrm{GC}^{5,6}$, $\mathrm{HPLC}^{7,8}$, voltammetry ${ }^{9,10}$, chemiluminesence $^{11}$, fluorimetry ${ }^{12,13}$. However, they are not very sensitive and are subject to 
numerous interferences and expensive. Spectrophotometric kinetic analytical methods become important means in trace analysis as various methods have been reported for the determination of trace amount of numerous elements ${ }^{14-16}$. Spectrophotometric catalytic kinetic methods are based on the catalytic effect of the element upon the reactions in colored (Vis) or colorless (UV) solutions ${ }^{17}$. The application of these methods offered some specific advantages such as improved selectivity and high sensitivity. In the past years, kinetic methods have been widely used in catalytic and non-catalytic determinations of various chemicals. Nevertheless, quite a few such methods have been published up to now. They are either narrow linear range ${ }^{18,19}$, subject to interference from other compounds ${ }^{18-21}$ or have a high limit of detection ${ }^{22-25}$. Here, we report a kinetic method for ultra trace determination of formaldehyde, based on its catalytic effect on the oxidation of safranin by $\mathrm{KBrO}_{3}$ in acidic medium. It should be noted that, there are no reports on the use of catalytic effect of formaldehyde for this reaction.

\section{Experimental}

Doubly distilled water and analytical reagent grade chemicals were used during all of the experimental studies. Safranin O solution $5.7 \times 10^{-4} \mathrm{M}$ was prepared by dissolving $0.020 \mathrm{~g}$ of dimethyl safranin O chloride (Merck) in water and solution diluting to $100 \mathrm{~mL}$ volumetric flask.

Bromate stock solution $0.015 \mathrm{M}$, was prepared by dissolving $0.626 \mathrm{~g}$ of potassium Bromate $(\mathrm{M}=167)$ in water and diluting to $250 \mathrm{~mL}$ in a $250 \mathrm{~mL}$ volumetric flask. An aqueous formaldehyde stock solution, $1000 \mu \mathrm{g} \mathrm{mL} \mathrm{m}^{-1}$, was prepared by diluting $2.5 \mathrm{~mL}$ of $37 \% \mathrm{w} / \mathrm{v}$ stock formaldehyde solution to $1 \mathrm{~L}$ with water. Sulfuric acid solution was prepared by appropriate dilution of concentrated sulfuric acid (Merck).

Stock solution $(1000 \mu \mathrm{g} / \mathrm{mL})$ of interfering ions were prepared by dissolving suitable salts in water, hydrochloric acid or sodium hydroxide solution. All glassware were cleaned with detergent solution, rinsed with tap water, soaked in dilute $\mathrm{HNO}_{3}$ solution $(2 \% \mathrm{~V} / \mathrm{V})$, rinsed with water and dried.

\section{Appartus}

Absorption spectra were recorded with a CECIL model 7500 spectrophotometer with a $1.0 \mathrm{~cm}$ quartz cell. A model $2501 \mathrm{CECIL}$ Spectrophotometer with $1.0 \mathrm{~cm}$ glass cuvettes was used to measure the absorbance at a fixed wavelength of at $564 \mathrm{~nm}$. A thermostat water bath (Gallen Kamp Griffin, BGL 240 V) was used to keep the reaction temperature at $28{ }^{\circ} \mathrm{C}$. A stopwatch was used for recording the reaction time.

\section{Recommended procedure}

All the solutions and distilled water were kept in a thermostated water batch at $28{ }^{\circ} \mathrm{C}$ for $20 \mathrm{~min}$ for equilibration before starting the experiment. An aliquot of the solution containing $0.2-15 \mu \mathrm{g} \mathrm{mL}^{-1}$ formaldehyde was transferred into a $10 \mathrm{~mL}$ volumetric flask and then $2.4 \mathrm{~mL} 5 \mathrm{M} \mathrm{H}_{2} \mathrm{SO}_{4}$ and $0.6 \mathrm{~mL} 5.7 \times 10^{-4} \mathrm{M}$ safranin were added to the flask. The solution was diluted to ca. $7 \mathrm{~mL}$ with water. Then, $2 \mathrm{~mL} 0.015 \mathrm{M}$ bromate was added and the solution was diluted to the mark with water. The solution was mixed and a portion of the solution was transferred to the spectrophotometer cell. The reaction was followed by measuring the decrease in absorbance of the solution against water at $533 \mathrm{~nm}$ for 0.5-1.5 min from initiation of the reaction. This signal (sample signal) was labeled as $\Delta \mathrm{A}_{\mathrm{s}}$. The same procedure was repeated without addition of formaldehyde solution, and the signal(blank signal) was labeled as $\Delta \mathrm{A}_{\mathrm{b}}$. Time was measured just after the addition of last drop of bromate solution. Analytical signal was deference between sample signal and blank signal $\left(\Delta \mathrm{A}_{\mathrm{s}-} \Delta \mathrm{A}_{\mathrm{b}}\right)$. 


\section{Results and Discussion}

Safranine is a dye that can be oxidized with strong oxidizing agents at slow reaction. We found that trace amount of formaldehyde have a catalytic effect on the oxidation of safranin by bromate in acidic medium.Therefore, by measuring the decrease in absorbance of safranin for a fixed time of $0.5-1.5 \mathrm{~min}$ initiation of the reaction, the formaldehyd contents in the sample can be measured, this reaction rate is sharply increased by addition of trace amounts of formaldehyde. The rate equation of the catalyzed reaction is:

$$
\text { Rate }=-\mathrm{d}[\text { safranin }] / \mathrm{dt}=\mathrm{K}[\text { formaldehyde }][\text { safranin }]^{\mathrm{m}}\left[\mathrm{BrO}_{3}{ }^{-}\right]^{\mathrm{n}}
$$

Were $\mathrm{k}$ is the rate constant. because $\left[\mathrm{BrO}_{3}{ }^{-}\right.$], [safranin], $\mathrm{BrO}_{3}{ }^{-}$can be considered to be constant and $\mathrm{m}$ was found to be 1. By integration of Eq[1] and by incorporating Beer's law, we obtain the final expression:

$$
\Delta \mathrm{A}=\mathrm{K}[\text { formaldehyde }] \mathrm{t}
$$

Where $t$ is the reaction time.

There are many methods, such as fixed-time, initial rate, rate constant and variable time methods for measuring the catalytic species. Among these, the fixed time method is the most conventional and simplest, involving the measurement of $\Delta \mathrm{A}$ at $533 \mathrm{~nm}$ (Figure 1). Safranin has the following structure ( Figure 2)
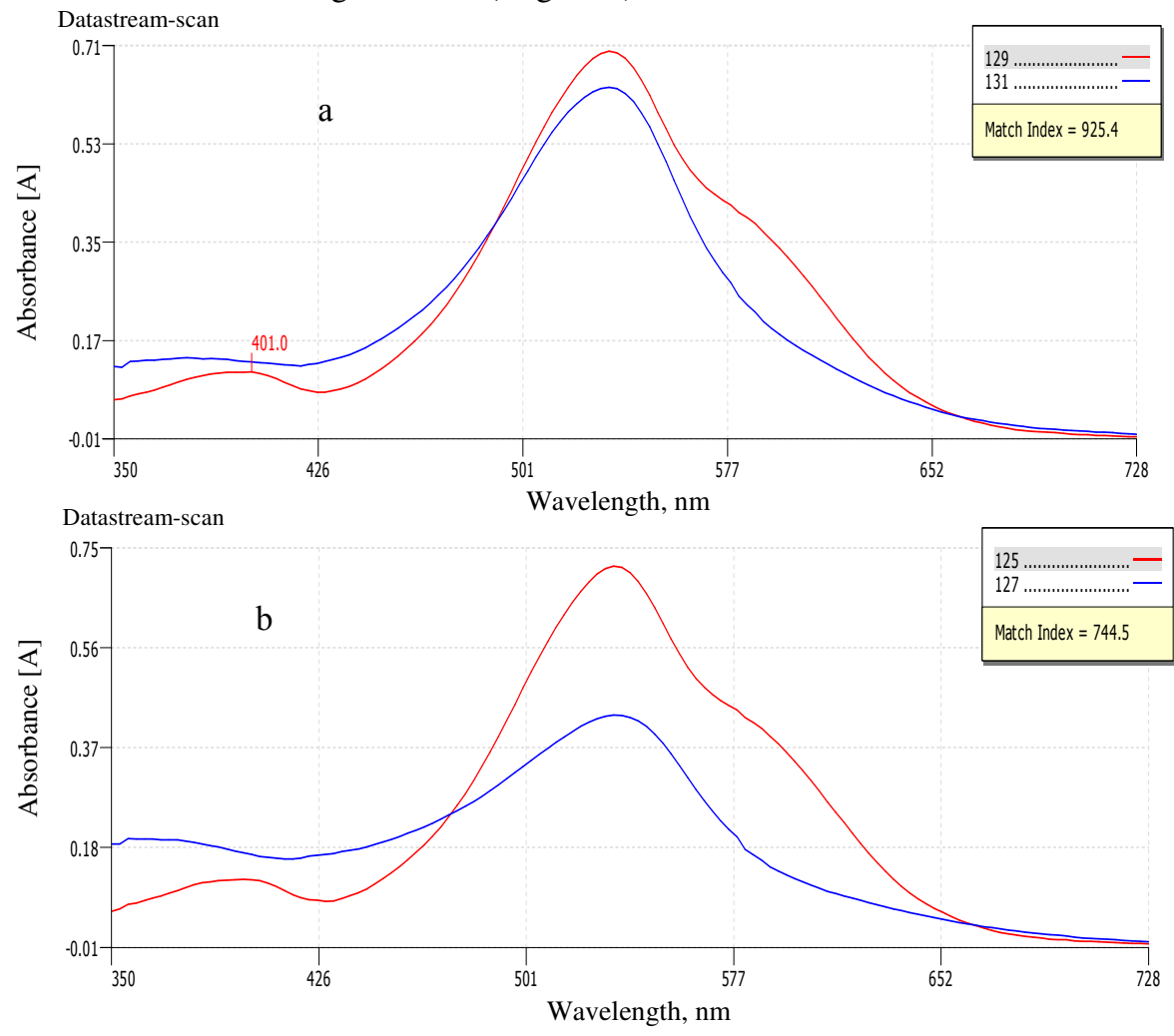

Figure 1. Absorption spectrum for the formaldehyde-safranin- $\mathrm{BrO}_{3}{ }^{-}$system with time. Conditions: $\mathrm{H}_{2} \mathrm{SO}_{4}, 1.2 \mathrm{M}$; safranin, $7.36 \times 10^{-4} \mathrm{M}$; $\mathrm{BrO}_{3}{ }^{-} 3.0 \times 10^{-3} \mathrm{M}$; temperature, $28{ }^{\circ} \mathrm{C}$; interval time for each scan, $0.5,1.5$ and 2.5 from initiation of the reaction. (a) in absence of formaldehyde (b) in presence of $0.4 \mu \mathrm{g} / \mathrm{mL}$ of formaldehyde 


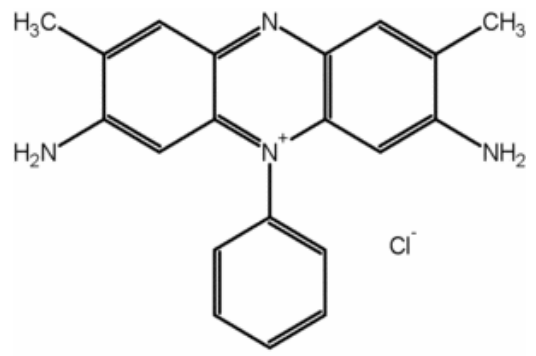

Figure 2. Structure of safranin

\section{Influence of variables}

In order to take full advantage of the procedure, the reagent concentrations must be optimized. The effect of sulphoric acid concentration, safranin concentration, bromate concentration, and temperature on analytical signal was studied.

The effect of sulfuric acid concentration on the analytical signal was studied in the range of 0.8-1.4 M (Figure 3). The results show that the analytical signal increases with increasing sulfuric acid concentration up to $1.2 \mathrm{M}$ and decreases at higher concentrations. Therefore, a sulfuric acid concentration of 1.2 $\mathrm{M}$ was selected for further study.

The influence of safranin concentration on the analytical signal was studied in the concentration range of $2.3 \times 10^{-5}-5.7 \times 10^{-5} \mathrm{M}$ (Figure 4). The results show that analytical signal increases with increasing safranin concentration up to $3.4 \times 10^{-5} \mathrm{M}$ and decreases at higher concentrations. Therefore, safranin concentration of $3.4 \times 10^{-5} \mathrm{M}$ was selected for further study.

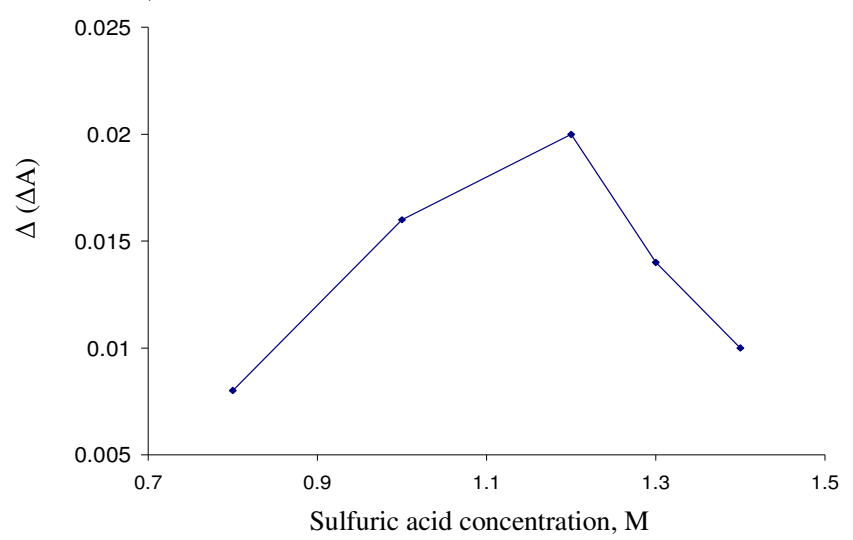

Figure 3. Effect of $\mathrm{H}_{2} \mathrm{SO}_{4}$ concentration on the analytical signal. Conditions: Safranin, $3.4 \times 10^{-5} \mathrm{M} ; \mathrm{BrO}_{3}{ }^{-} 2.7 \times 10^{-3} \mathrm{M}$; formaldehyde $0.4 \mu \mathrm{g} / \mathrm{mL}$, temperature, $28{ }^{\circ} \mathrm{C}$ and time of $1.0 \mathrm{~min}$ from initiation of the reaction

Figure 5 shows the effect of the bromate concentration on the analytical signal for the range of $2.4 \times 10^{-3}-3.3 \times 10^{-3} \mathrm{M}$. This analytical signal increases with increasing bromate concentration up to $3 \times 10^{-3} \mathrm{M}$ and decreases at higher concentrations.. Therefore, a final concentration of $3 \times 10^{-3} \mathrm{M}$ of bromate was selected as the optimum concentration.

The effect of the temperature on the analytical signal was studied in the range $20-40{ }^{\circ} \mathrm{C}$ with the optimum of the reagents concentrations. The results showed that, as the temerature increases up to $28^{\circ} \mathrm{C}$, the analytical signal increases, whereas higher temperature values decrease the analytical signal $\left(\Delta \mathrm{A}=\Delta \mathrm{A}_{\mathrm{s}}-\Delta \mathrm{A}_{\mathrm{b}}\right)$. Therefore, $28^{\circ} \mathrm{C}$ was selected for further study. 


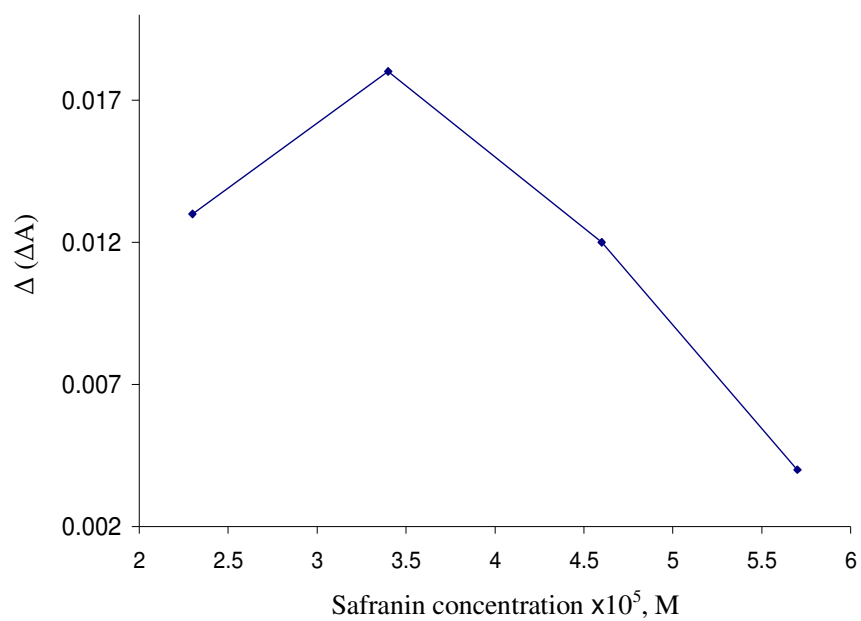

Figure 4. Effect of safranin concentration on the analytical signal. Conditions: $\mathrm{H}_{2} \mathrm{SO}_{4}, 1.2 \mathrm{M}$; $\mathrm{BrO}_{3}{ }^{-}, 2.7 \times 10^{-3} \mathrm{M}$, formaldehyde $0.4 \mu \mathrm{g} / \mathrm{mL}$, temperature, $28{ }^{\circ} \mathrm{C}$ and time of $1.0 \mathrm{~min}$ from initiation of the reaction.

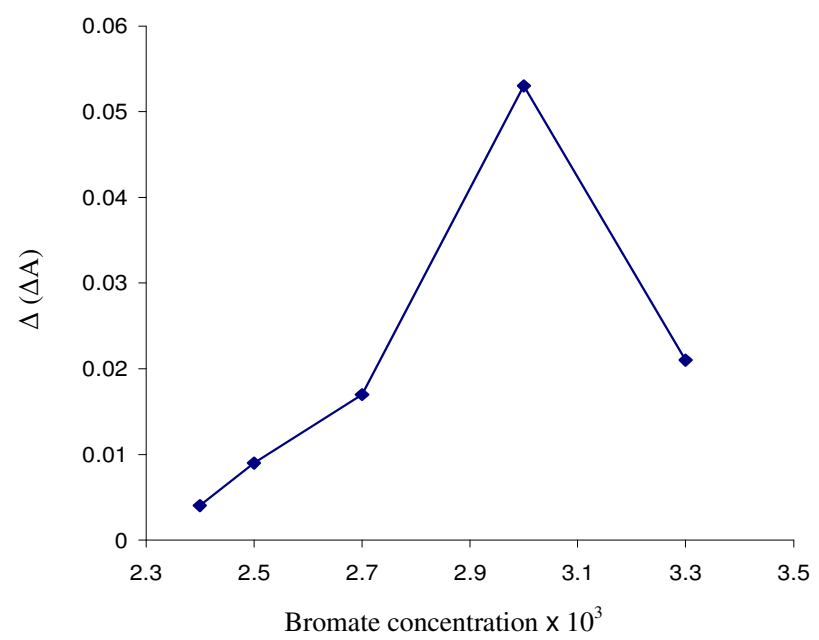

Figure 5. Influence of $\mathrm{BrO}_{3}{ }^{-}$concentration on the analytical signal. Conditions: $\mathrm{H}_{2} \mathrm{SO}_{4}, 1.2 \mathrm{M}$; safranin, $3.4 \times 10^{-5} \mathrm{M}$ formaldehyde $0.4 \mu \mathrm{g} / \mathrm{mL}$; temperature, $28{ }^{\circ} \mathrm{C}$ and time of $1.0 \mathrm{~min}$ from initiation of the reaction.

\section{Calibration graph, precision and limit of detection}

Calibration graph were obtained using the fixed time method. This method was applied to the change in absorbance over an interval of 0.5-1.5 min from intiation of the reaction because it provided the best regresion and sensitivity. Under the optimum conditions described above, a linear calibration range $0.020-1.5 \mu \mathrm{g} / \mathrm{mL}$ of formaldehyde. The equation of the calibration graph is $\Delta \mathrm{A}=0.0835 \mathrm{C}+0.0194(\mathrm{n}=8, \mathrm{r}=0.9997)$. The calibration graph was constructed by plotted of $\Delta \mathrm{A}_{\mathrm{s}}$ at a fixed-time method versus formaldehyde concentration. The experimental $3 \delta$ limit of detection was $9.5 \mathrm{ng} / \mathrm{mL}$. The relative standard deviation of five replicate measurements is $2.3 \%$ for $0.5 \mu \mathrm{g} \mathrm{mL}^{-1}$ of formaldehyde. 


\section{Interference study}

In order to assess the application of the proposed method to synthetic samples, the effect of various ions on the determination of $0.6 \mu \mathrm{g} / \mathrm{mL}$ formaldehyde was studied. The tolerance limit was defined as the concentration of a added ions causing a relative error less than $3 \%$ the results are summarized in Table 1 . The results show that method is relatively selective for formaldehyde determination.

Table 1. Effect of foreign ions on the determination of $0.6 \mu \mathrm{g} / \mathrm{ml}$ formaldehyde

\begin{tabular}{cc}
\hline Species & Tolerance Limit $\left(\mathrm{w}_{\text {ion }} / \mathrm{w}_{\text {formaldehyde }}\right)$ \\
\hline $\mathrm{Na}^{+}, \mathrm{K}^{+}, \mathrm{Mo}(\mathrm{IV}), \mathrm{NH}_{4}^{+}, \mathrm{Fe}^{3+}, \mathrm{Fe}^{2+}, \mathrm{Rb}^{+}, \mathrm{Cs}^{+}, \mathrm{Al}^{+3}$ & 1000 \\
$\mathrm{HSO}_{4}{ }^{-}, \mathrm{CO}_{3}{ }^{2-}, \mathrm{HCO}{ }_{3}^{-}, \mathrm{PO}_{4}^{-3}$, Tatarate, Borate, & 300 \\
Ethanol, methanol, ethanolamine & 200 \\
$\mathrm{Co}^{+2}$ & 100 \\
$\mathrm{~S}_{2} \mathrm{O}_{3}{ }^{2-}, \mathrm{SO}_{3}{ }^{2-}, \mathrm{I}^{-}$ & 50 \\
$\mathrm{Br}^{-}$ & \\
\hline
\end{tabular}

Sample analysis

In order to evaluate the applicability of the proposed method, water samples were analyzed to determine formaldehyde contents. The results are presented in Table 2. Good recoveries with precise results show good reproducibility and accuracy of the method. Table 2.

Table 2. Determination of formaldehyde in synthetic samples

\begin{tabular}{ccccc}
\hline Sample & $\begin{array}{c}\text { formaldehyde } \\
\text { Added, ng/mL }\end{array}$ & $\begin{array}{c}\text { formaldehyde } \\
\text { Found, ng/mL }\end{array}$ & $\begin{array}{c}\text { Recovery } \\
\%\end{array}$ & $\begin{array}{c}\text { RSD } \\
\mathrm{n}=4\end{array}$ \\
\cline { 1 - 4 } Well water & - & - & - & - \\
Well water & 60 & 64 & 106.6 & 2.1 \\
Well water & 300 & 291 & 97 & 2.9 \\
Well water & 800 & 825 & 103.1 & 2.6 \\
\hline
\end{tabular}

\section{Conclustion}

The catalytic spectrophotometric method developed for the determination of formaldehyde is inexpensive, uses readily available reagents, allows rapid determination at low operating costs, and shows simplicity, adequate selectivity, low limit of detection and good precision and accuracy compared to other kinetic procedures.

\section{Aeknowledgments}

The author are Thankful to the Islamic Azad University-Majlesi Branch for the support of this work.

\section{Refrences}

1. Agathos M and Bernecker H A, Derm Beruf Umwelt., 1982, 30(2), 43.

2. Cockcroft D W and Hoeppner V H, Dolvovich J Chest., 1982, 82, 49.

3. Frankel L S, McCallum K S and Collier L, Environ Sci Technol., 1974, 8, 356-359

4. Kallos G J and Solomon R A, Am Ind Hyg Assoc J., 1973, 34(11), 469-473.

5. Kennedy E R and Hill R H, Anal Chem., 1982, 54,1739.

6. $\quad$ Neitzert V and Seiler W, Geophys Res Lett., 1981, 8(1),79-82.

7. $\quad$ Fung K and Grosjean D, Anal Chem., 1981, 53,168-171.

8. Salas L J and Singh H B, Atoms Environ., 1986, 20,1301-1304. 
9. Septon J C and Ku J C, Am Ind Hyg Assoc J., 1982, 43, 845.

10. Li W, Chen X and Cheng Z, Huanjing Huaxue., 1988, 7, 53.

11. Xiaohu L, Minggang L and Fang Y, Anal Lett., 1992, 25, 2073.

12. Bisgaard P, Molhave L, Rietz B and Wilhardt P, Anal Lett., 1983,16, 1457.

13. Dong S and Dasgupta P K, Environ Sci Technol., 1987, 21, 581-588.

14. Afkhami A, Madrakian T and Assl A.A, Talanta, 2001, 55(1), 55-60.

15. Ghasemi Jand Mohammadi D E, Microchem J., 2002,71, 1

16. Khajehsharifi H, Mousavi M F, Ghasemi J and Shamsipur M, Anal Chim Acta 2004, 512, 369.

17. Rancic S M, Nikolic-Mandicb S D and Mandic L M, Anal Chim Acta., 2005, 547(1), 144.

18. Fan J, Tang Y J and Feng S L, Int J Environ Anal Chem., 2002, 82, 361.

19. Abbasi S, Esfandyarpour M, Taher M A, Daneshfar A, Spectrochim Acta Part A: Mol Biomol Spectrosc., 2007, 67,578.

20. Fan J, Tang Y J and Feng S L, Chin J Anal Chem., 2002, 30, 942-945.

21. Maeda Y, Hu X C, ITou S, Kitano M, Takenaka N, Bandow H and Munemori M, Analyst, 1994, 119, 2237.

22. Pourreza N, Parham H and Cheraghi S, Asian J Chem., 2004,16,1605.

23. Feng S L, Fan J, Wang A J, Chen X G and.Hu Z D, Anal Lett., 2004, 37, 2545.

24. Wang S H, Du L Y and Zhang A M, Chin J Anal Chem., 2000, 28, 628-630.

25. Huang X Y and Xu C X, Chin J Anal Chem., 2004, 32(7), 978. 


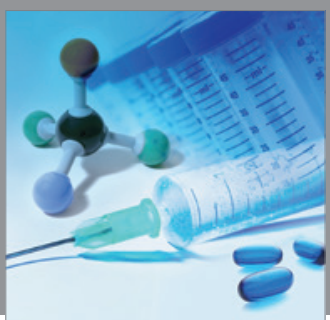

International Journal of

Medicinal Chemistry

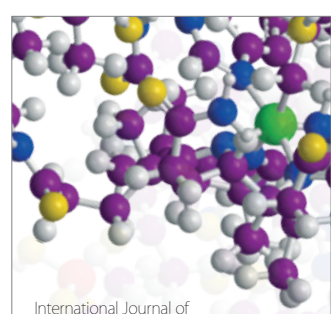

Carbohydrate Chemistry

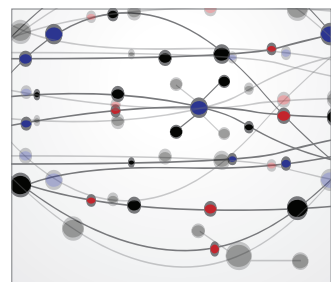

The Scientific World Journal
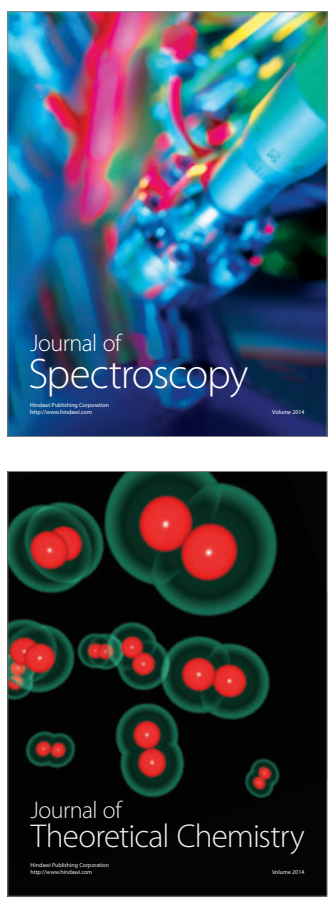
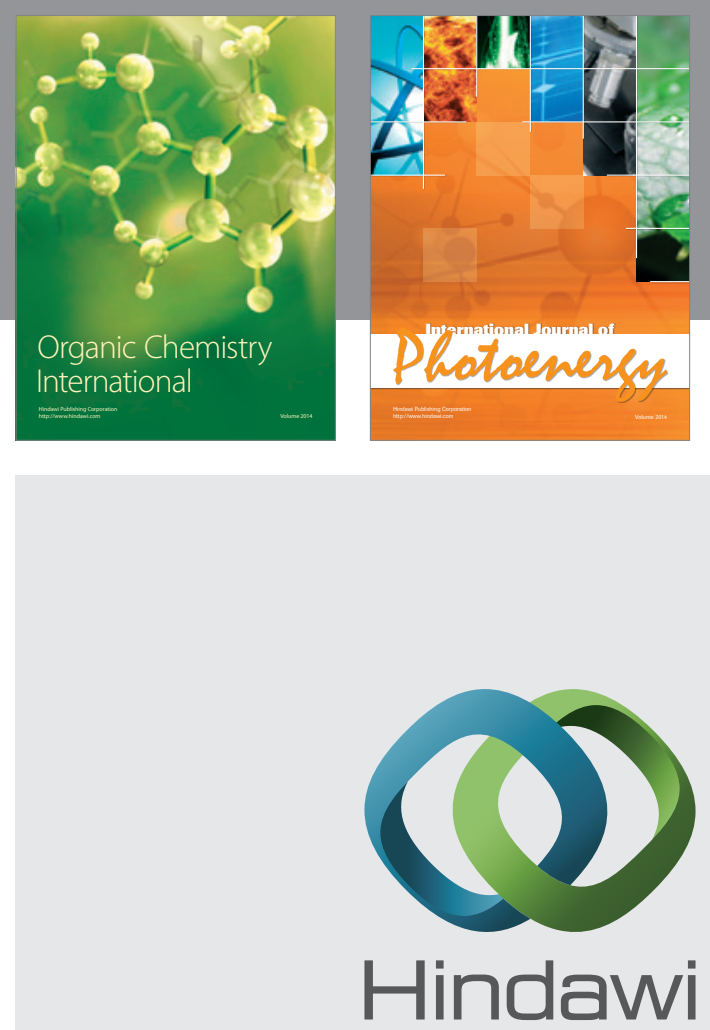

Submit your manuscripts at

http://www.hindawi.com
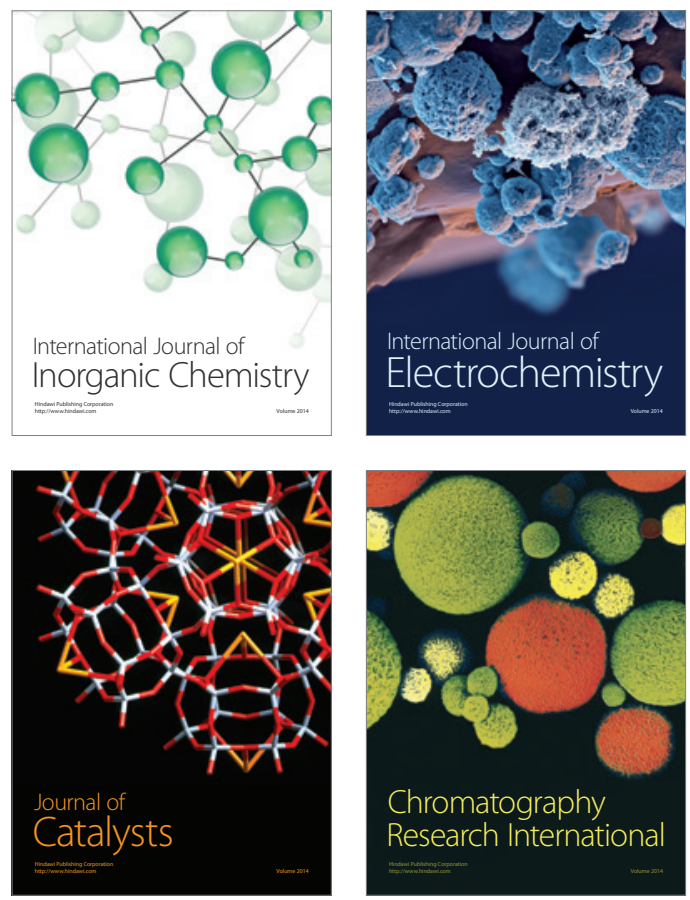
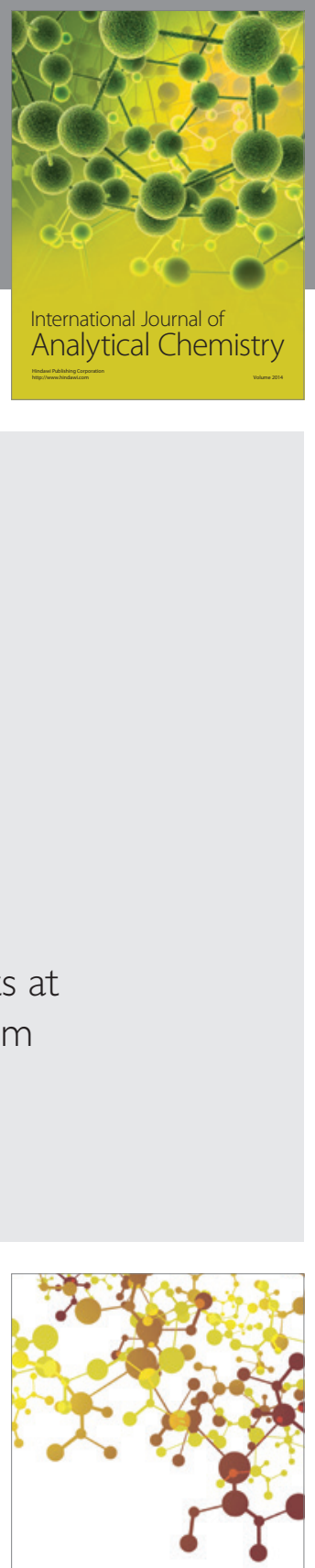

Journal of

Applied Chemistry
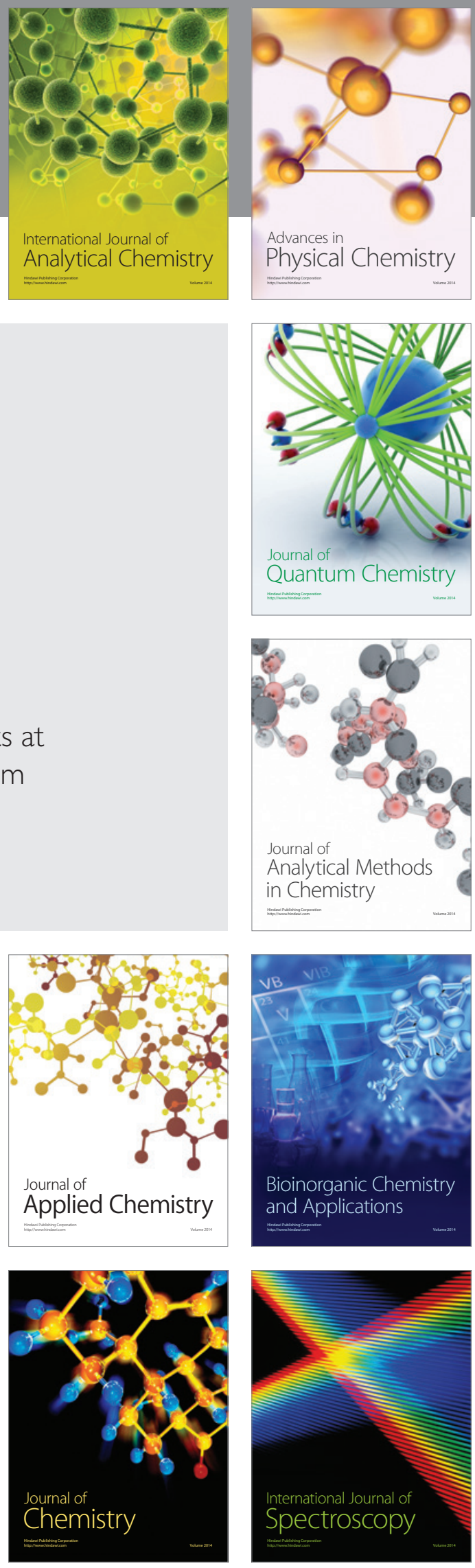